\title{
Implantação dos componentes I, II e III do Programa Saúde na Escola
}

Implementation of components I, II and III of the School Health Program

Implementación de los componentes I, II y III del Programa Salud en la Escuela

\author{
Rosa Maria RODRIGUES ${ }^{(1)}$ \\ Gilson Fernandes da SILVA ${ }^{(2)}$ \\ Solange de Fátima Reis CONTERNO ${ }^{(1)}$ \\ Claudia Silveira VIERA ${ }^{(1)}$ \\ Lourdes $\mathrm{MISSIO}^{(3)}$
}

Recebido: 28 fev 2020

Revisado: 19 abr 2020

Aceito: 12 maio 2020

Autor de correspondência:

Rosa Maria Rodrigues rmrodri09@gmail.com

Conflito de interesses:

Os autores declaram não haver nenhum interesse profissional ou pessoal que possa gerar conflito de interesses em relação a este manuscrito.

\section{Resumo}

A educação e a saúde se encontram no ambiente escolar para desenvolver ações de saúde, as quais precisam acontecer orientadas pelo conceito ampliado de saúde. Desde 2007, este encontro é guiado pelo Programa Saúde na Escola, pela primeira vez articulando oficialmente ações de saúde e educação no território nacional. O objetivo foi identificar como estão sendo desenvolvidas as ações dos componentes I, II e III do Programa Saúde na Escola. Trata-se de estudo exploratório através de pesquisa documental com dados referentes a cinco municípios da região Oeste do Paraná acessados em Portarias e no Sistema Integrado de Monitoramento e Controle, distribuídos em frequências e analisados a luz da literatura pertinente. Os municípios pactuaram expressivamente ações no componente I, destacando-se as ações assistenciais. No componente II pactuaram as ações de promoção da segurança alimentar e alimentação saudável, bem como as de prevenção nas escolas: direito sexual e reprodutivo e prevenção de DST/AIDS. As atividades do componente III foram as menos pactuadas e realizadas, especialmente nos municípios menores. A implantação do PSE nos municípios estudados precisa ser fortalecida requerendo organização institucional para o desenvolvimento dos componentes previstos.

Descritores: Educação; Saúde; Serviços de Saúde Escolar. 


\title{
Abstract
}

Education and health are in the school environment to develop health actions, which need to be guided by the expanded concept of health. Since 2007, this collaboration has been guided by the Health in School Program, for the first time officially articulating health and education actions in the national territory. The objective of this work was to identify how the actions of components I, II and III of the PSE are being developed. This is an exploratory study carried out through documentary research with data referring to five municipalities in the western region of Paraná accessed in ordinances and in the Integrated Monitoring and Control System, distributed in frequencies and analyzed in the light of the pertinent literature. The municipalities expressly agreed actions in component I, highlighting the assistance actions. In component II, agreed the actions to promote food security and healthy eating, as well as prevention in schools: sexual and reproductive rights and STD/AIDS prevention. The activities of component III were the least agreed and performed, especially in the smaller municipalities. The implementation of the PSE in the studied municipalities needs to be strengthened by requiring an institutional organization for the development of the planned components.

Keywords: Education; Health; School Health Services.

\begin{abstract}
Resumen
La educación y la salud se encuentran en el entorno escolar para desarrollar acciones de salud, que deben realizarse guiadas por el concepto ampliado de salud. Desde 2007, esta reunión ha sido guiada por el Programa Salud en la Escuela, por primera vez articulando oficialmente acciones de salud y educación en el territorio nacional. El objetivo era identificar cómo se están desarrollando las acciones de los componentes I, II y III del Programa Salud en la Escuela. Este es un estudio exploratorio a través de la investigación documental con datos que se refieren a cinco municipios en la región occidental de Paraná accedidos en las ordenanzas y en el Sistema Integrado de Monitoreo y Control, distribuidos en frecuencias y analizados a la luz de la literatura relevante. Los municipios han acordado significativamente las acciones en el componente I, con énfasis en las acciones de asistencia. En el componente II, acordado las acciones para promover la seguridad alimentaria y la alimentación saludable, así como la prevención en las escuelas: derechos sexuales y reproductivos y prevención de EST/SIDA. Las actividades del componente III fueron las menos acordadas y realizadas, especialmente en municipios más pequeños. La implementación del PSE en los municipios estudiados debe fortalecerse, lo que requiere una organización institucional para el desarrollo de los componentes planificados.
\end{abstract}

Palabras-claves: Educación; Salud; Servicios de Salud Escolar.

\section{Introdução}

Saúde e educação são serviços organizados para reprodução de grupos ou populações, reconhecidamente fundamentais nas sociedades modernas. Quando tratada no ambiente da escolarização formal, a relação saúde-educação toma contornos específicos, delimitando um cenário em que profissionais de saúde e educação devem se encontrar no qual, políticas públicas específicas devem ser propostas e implementadas.

Saúde escolar é, nessa perspectiva, o encontro entre os saberes e as práticas de profissionais da saúde e da educação, visando o desenvolvimento das ações dos dois campos, que se tocam diretamente. Este encontro deve estar alicerçado em uma concepção ampliada do processo saúde-doença e educação, produzindo ações que contribuam para a emancipação dos escolares; além disso, deve objetivar torná-los sujeitos e não objetos, tomados como depositários de ações de saúde, no ambiente privilegiado 
ISSN 2179-6750

que é a escola. No contexto escolar, estão reunidos, para fácil acesso, um grupo populacional importante, que é visto como passível de ser educado, a fim de reproduzir sua existência de forma saudável.

Uma concepção ampliada do processo saúde-doença considera que a saúde não é resultado exclusivo da assistência prestada por pessoal especializado, mas se conforma no acesso a alimentação, moradia, transporte, saneamento, trabalho, lazer e demais elementos sociais, políticos e econômicos que gerem ambientes promotores da saúde. Assim, não se confunde com a determinação de fatores de risco exclusivamente individuais, mas coletivos, para os quais a promoção da saúde é importante conceito e ferramenta. ${ }^{1}$

A emergência das ações de saúde na escola data do final do século XVIII e início do século XIX, na Alemanha, a partir da elaboração do Sistema Frank, pelo médico alemão Johann Peter Frank, que levava em consideração, além da saúde escolar, aspectos da saúde pública e individual, tais como os sociais, culturais, biológicos, econômicos,

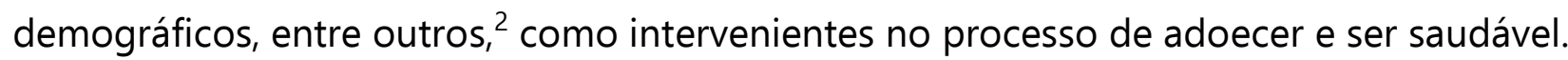

Na contemporaneidade, as ações oficiais, que deram a conotação à saúde escolar, pautada na promoção da saúde, tiveram início nos anos de 1990, quando a Organização Pan Americana da Saúde, em 1995, criou a Rede de Escolas Promotoras da Saúde incentivando os países a conformarem suas políticas públicas de saúde escolar, ancoradas nesse referencial. A partir de então, estabeleceram-se as orientações para a criação de Escolas Promotoras de Saúde - EPS. ${ }^{3}$

No Brasil, tais orientações ganharam ressonância em 2005, somadas a outros movimentos que, desde o século passado, buscavam viabilizar ações de saúde no espaço escolar, quando o Governo Federal emitiu a Portaria Ministerial n. 749/2005, ${ }^{4}$ constituindo a Câmara Intersetorial para a elaboração de diretrizes, que subsidiariam a Política Nacional de Educação em Saúde na Escola. Esta legislação foi substituída, em 2006, pela Portaria Interministerial n. 1.820/2006, ${ }^{5}$ para constituir a gestão da Câmara de forma compartilhada entre os Ministérios da Saúde - MS e Ministério da Educação - MEC, indicando um princípio fundamental da saúde escolar, a intersetorialidade, posteriormente, inserida nos documentos oficiais.

A saúde escolar se oficializou em uma política pública no ano de 2007, quando, o Decreto n. 6.286 de 5 de dezembro de 2007 instituiu o Programa Saúde na Escola - PSE ${ }^{6}$ revisado em alguns aspectos pela Portaria MS/MEC n. 1.413/2013. ${ }^{7}$ Registram-se os alicerces do PSE, que servem como elementos balizadores de sua análise, quais sejam: a intersetorialidade; a conformidade com os princípios do Sistema Único de Saúde - SUS, com destaque para a integralidade, quando prevê que as ações contemplem a atenção, 
promoção, prevenção e assistência à saúde dos escolares e a promoção da saúde, conceito articulador das iniciativas de estruturação de políticas para o ambiente escolar.

A integralidade implica em repensar a organização do processo de trabalho, gestão, planejamento com a construção de saberes e práticas de saúde. A mudança no modelo de atenção à saúde propõe não apenas a priorização da atenção primária, mas o usuário como um cidadão integral superando a fragmentação do cuidado que transforma as pessoas em órgãos, sistemas ou dissocia as dimensões sociais, culturais, biológicas ou psicológicas do ser humano. ${ }^{8}$

A intersetorialidade ganha visibilidade na implementação do PSE ao exigir a articulação entre os setores saúde e educação. Como as questões que colonizam o ambiente escolar são multidimensionais, as ações a serem implementadas devem extrapolar setores únicos. Se entre os profissionais da saúde o termo intersetorialidade é bem compreendido, o mesmo é visto com certa estranheza entre os profissionais de educação. No entanto, o atribuem à noção de parceria, indicando a necessidade do trabalho conjunto diante da complexidade dos problemas sociais existentes potencializando as chances de melhores resultados. ${ }^{9}$

O conceito de promoção da saúde é estruturante das ações; definida pela Organização Mundial da Saúde, a promoção da saúde é um processo que objetiva ampliar as possibilidades das pessoas de controlar os determinantes sociais da saúde, melhorando a qualidade de vida, garantindo a todos os educandos a oportunidade de fazerem escolhas favoráveis à saúde, pelo protagonismo na produção da saúde. ${ }^{10}$

O PSE estrutura-se em três componentes; o componente I abarca as ações de avaliação clínica e psicossocial dos escolares; no componente II estão as de promoção e prevenção à saúde e, no componente III, as de formação dos profissionais envolvidos em sua execução. ${ }^{10}$ Questiona-se, neste estudo, como tem ocorrido a implantação do PSE tendo como objetivo identificar como estão sendo desenvolvidas as ações dos componentes I, II e III do Programa Saúde na Escola em uma realidade específica.

\section{Metodologia}

Estudo exploratório através de pesquisa documental explorando dados referentes a cinco municípios da região Oeste do Paraná, que integram a 10 a Regional de Saúde e o Núcleo Regional de Educação de Cascavel/PR, descritos no Quadro 1, que fizeram adesão ao Programa Saúde na Escola e iniciaram a implantação, até o ano de 2012. Estão designados como M1, M2, M3, M4, M5. 
ISSN 2179-6750

Quadro 1. Municípios, população, área territorial, instituições de saúde do Sistema Único de Saúde, Índice de Desenvolvimento Humano Municipal e alunos matriculados na pré-escola, ensino fundamental, e ensino médio. Cascavel/PR, 2016.

\begin{tabular}{|l|c|c|c|c|c|c|c|}
\hline \hline $\begin{array}{l}\text { Variáveis/ } \\
\text { Municípios }\end{array}$ & População & Área territorial $\mathrm{Km}^{2}$ & $\begin{array}{c}\text { Instituições de } \\
\text { saúde }\end{array}$ & \multicolumn{2}{|c|}{$\begin{array}{c}\mathrm{IDHM}^{*} \\
2010\end{array}$} & \multicolumn{2}{|c|}{ Alunos matriculados } \\
\hline & & & & & $\mathrm{PE}^{\star *}$ & $\mathrm{EF}^{\star *}$ & $\mathrm{EM}^{\star *}$ \\
\hline M1 & 2.874 & 102,647 & 1 & 0,695 & 66 & 359 & 137 \\
\hline M2 & 7.911 & 256,297 & 5 & 0,670 & 186 & 1.243 & 383 \\
\hline M3 & 14.582 & $1.225,606$ & 16 & 0,677 & 234 & 1.854 & 644 \\
\hline M4 & 3.925 & 116,858 & 3 & 0,687 & 127 & 491 & 152 \\
\hline M5 & 11.824 & 504,171 & 7 & 0,681 & 293 & 1.568 & 643 \\
\hline \hline
\end{tabular}

Fonte: IBGE (2016). ${ }^{11}$

* Índice de Desenvolvimento Humano Municipal.

** PE: Pré-Escola; EF: Ensino Fundamental; EM: Ensino Médio.

As metas de cobertura das ações do Programa Saúde na Escola são pactuadas através do Termo de Compromisso, no qual os gestores elencam as metas anuais de cobertura dos escolares beneficiados. ${ }^{7}$ As metas pactuadas e cumpridas, relativas aos componentes II e III foram acessadas por meio do Sistema Integrado de Monitoramento Execução e Controle - Simec. As relacionadas ao componente I são registradas no e-SUS (sistema de gerenciamento de informações do SUS) e são alimentadas pelos serviços de saúde, não sendo disponíveis para consulta pública, pois até a coleta de dados o Ministério da Saúde não havia publicado relatórios nacionais das ações do PSE. Apresentam-se dados do componente I pactuados no ano de 2015, os quais foram acessados através dos Termos de Compromisso assinados entre as gestões municipais, estadual e federal, fornecidos pelas Secretarias de Saúde. Além desses dados, Portarias Ministeriais foram emitidas com os recursos e pactuação de ações para o PSE sendo tomadas como fontes de dados.

As informações foram sistematizadas em séries de valores numéricos e distribuídas em frequência, descritos e analisados à luz da literatura pertinente, tendo como categorias analíticas $^{12}$ a intersetorialidade, a integralidade e a promoção da saúde. A pesquisa foi aprovada pelo Comitê de Ética em Pesquisa, conforme Parecer CEP n. 1.134.653/2015.

\section{Resultados}

\section{Os recursos federais para o Programa Saúde na Escola nos municípios pesquisados}

A Tabela 1 apresenta as informações sobre os recursos financeiros definidos para os municípios pesquisados, conforme publicado nas Portarias MS n. 3.014/2011, MS n. 524/2012, MS n. 2.608/2013 e MS n. 1.067/2015, ${ }^{13-16}$ mostrando que foi a partir de 2011 que os municípios estudados passaram a receber recursos do PSE. 
Tabela 1. Informações sobre recursos definidos para os municípios pesquisados, conforme a Portarias MS n. 3.014/2011, MS n. 524/2012, MS n. 2.608/2013 e n. 1.067/2015

\begin{tabular}{l|c|c|c|c|c|c}
\hline \hline Municípios & $\begin{array}{c}\text { Valor do } \\
\text { repasse em } \\
2011\end{array}$ & $\begin{array}{c}\text { Valor do } \\
\text { repasse em } \\
2012\end{array}$ & $\begin{array}{c}\text { Repasse de } \\
20 \% \text { do teto } \\
\text { em 2013 }\end{array}$ & $\begin{array}{c}\text { Total de } \\
\text { Educandos } \\
\text { pactuados } \\
\text { no PSE 2014 } \\
\text { a } 2015\end{array}$ & $\begin{array}{c}\text { Valor total } \\
\text { máximo a ser } \\
\text { repassado } \\
2014 \text { a } 2015\end{array}$ & $\begin{array}{c}20 \% \\
\text { corresponde } \\
\text { nte à adesão } \\
\text { em } 2014 \text { a } \\
2015\end{array}$ \\
\hline M1 & $\mathrm{R} \$ 6.700,00$ & - & $\mathrm{R} \$ 800,00$ & 612 & $\mathrm{R} \$ 4.000,00$ & $\mathrm{R} \$ 800,00$ \\
\hline $\mathrm{M} 2$ & - & - & $\mathrm{R} \$ 2.000,00$ & 1.578 & $\mathrm{R} \$ 8.000,00$ & $\mathrm{R} \$ 1.600,00$ \\
\hline $\mathrm{M} 3$ & $\mathrm{R} \$ 26.800,00$ & - & $\mathrm{R} \$ 3.400,00$ & 2.975 & $\mathrm{R} \$ 15.000,00$ & $\mathrm{R} \$ 3.000,00$ \\
\hline $\mathrm{M} 4$ & $\mathrm{R} \$ 13.400,00$ & - & $\mathrm{R} \$ 1.000,00$ & 785 & $\mathrm{R} \$ 4.000,00$ & $\mathrm{R} \$ 800,00$ \\
\hline $\mathrm{M} 5$ & $\mathrm{R} \$ 20.100,00$ & - & $\mathrm{R} \$ 1.400,00$ & 1.144 & $\mathrm{R} \$ 6.000,00$ & $\mathrm{R} \$ 1.200,00$ \\
\hline
\end{tabular}

Fonte: Brasil $(2011 ; 2012 ; 2013,2015) .{ }^{13-16}$

O PSE previa, conforme a Portaria Ministerial MS-1.413/2013, ${ }^{6}$ que após a pactuação das ações seria liberado o percentual de $20 \%$ dos recursos previstos, conforme o número de educandos e ações pactuadas. Modificou-se, assim, a partir de 2013, a forma do repasse dos recursos que antes eram integralmente repassados quando da pactuação, como se observa nas quatro últimas colunas da Tabela 1. De 2013 em diante, os municípios só acessariam os recursos em sua totalidade, caso cumprissem as ações pactuadas.

\section{O Programa Saúde na Escola nos termos de pactuação municipais e nos dados do Sistema Integrado de Monitoramento Execução e Controle}

A análise dos dados pactuados, conforme os termos de compromisso assinados pelos municípios, para o componente I, mostram que os cinco municípios, em 2015, contratuaram número expressivo de ações em todas as atividades necessárias para o cumprimento do PSE, neste componente. Excetuando-se para o M4 e M5, números inferiores ou ausência de pactuação nos itens: saúde auditiva, identificação de educandos com possíveis sinais de alterações na linguagem oral e identificação de possíveis sinais de agravos de saúde negligenciados e doenças em eliminação, como se observa no Quadro 2.

As ações pactuadas no componente II estão expostas no Quadro 3, contemplando os anos de 2013 a 2015, a partir dos dados acessados no Simec. Observa-se que as pactuações foram mais frequentes para os itens promoção da segurança alimentar e promoção da alimentação saudável e saúde e prevenção nas escolas (SPE): direito sexual e reprodutivo e prevenção de DST/Aids, os quais foram pactuados 11 vezes, nos três anos, pelos cinco municípios. A promoção das práticas corporais, atividade física e lazer nas 
escolas foi pactuada cinco vezes nos três anos pelos cinco municípios. Os M1 e M4, não as pactuaram em nenhum ano.

A ação promoção da cultura da paz e direitos humanos foi pactuada nove vezes, nos três anos, pelos cinco municípios e as ações promoção da saúde ambiental e desenvolvimento sustentável e saúde e prevenção nas escolas: prevenção ao uso de álcool, tabaco, crack e outras drogas, foram pactuadas oito vezes, nos três anos. Destaca-se que o M2 não pactuou a última ação em nenhum dos anos. Identifica-se que o M4 não pactuou nenhuma ação no componente II em 2013 e 2014, mostrando que não desenvolveu o PSE nesses anos.

Quadro 2. Ações dos componentes I pactuadas pelos Municípios 1, 2, 3, 4 e 5 conforme Termo de Compromisso do Programa Saúde na Escola. Cascavel/PR, 2015.

\begin{tabular}{|l|c|c|c|c|c|}
\hline \hline \multicolumn{1}{|c|}{ COMPONENTE I } & M1 & M2 & M3 & M4 & M5 \\
\hline $\begin{array}{l}\text { Avaliação } \\
\text { Antropométrica }\end{array}$ & $\begin{array}{l}\text { Educandos } \\
\text { pactuados }\end{array}$ & $\begin{array}{l}\text { Educandos } \\
\text { pactuados }\end{array}$ & $\begin{array}{c}\text { Educandos } \\
\text { pactuados }\end{array}$ & $\begin{array}{c}\text { Educandos } \\
\text { pactuados }\end{array}$ & $\begin{array}{c}\text { Educandos } \\
\text { pactuados }\end{array}$ \\
\hline $\begin{array}{l}\text { Avaliação da Saúde } \\
\text { Bucal }\end{array}$ & 612 & 1.578 & 3.246 & 785 & 1.144 \\
\hline Saúde Ocular & 612 & 1.578 & 3.246 & 785 & 1.144 \\
\hline $\begin{array}{l}\text { Verificação da situação } \\
\text { vacinal }\end{array}$ & 612 & 1.578 & 3.246 & 785 & 1.144 \\
\hline Saúde Auditiva & 612 & 1.578 & 117 & 87 & - \\
\hline $\begin{array}{l}\text { Identificação de } \\
\text { educandos com } \\
\text { possíveis sinais de } \\
\text { alterações de } \\
\text { linguagem oral }\end{array}$ & 612 & 1.464 & 117 & 87 & - \\
\hline $\begin{array}{l}\text { Identificação de } \\
\text { possíveis sinais de } \\
\text { agravos de saúde } \\
\text { negligenciados e } \\
\text { doenças em eliminação }\end{array}$ & 612 & 1.310 & 2.182 & & \\
\hline \hline
\end{tabular}

Fonte: Elaborado pelos autores (2016). 
ISSN 2179-6750

Quadro 3. Frequência das ações realizadas no componente II nos municípios 1, 2, 3, 4, 5. (Brasil, 2016)

\begin{tabular}{|c|c|c|c|c|c|c|c|c|c|c|c|c|c|c|c|}
\hline MUNICÍPIOS & \multicolumn{3}{|c|}{ M1 } & \multicolumn{3}{|c|}{ M2 } & \multicolumn{3}{|c|}{ M3 } & \multicolumn{3}{|c|}{ M4 } & \multicolumn{3}{|c|}{ M5 } \\
\hline $\begin{array}{c}\text { AÇÕES } \\
\text { REALZADAS }\end{array}$ & 2013 & 2014 & 2015 & 2013 & 2014 & 2015 & 2013 & 2014 & 2015 & 2013 & 2014 & 2015 & 2013 & 2014 & 2015 \\
\hline $\begin{array}{l}\text { Promoção da } \\
\text { Segurança } \\
\text { Alimentar e } \\
\text { Promoção da } \\
\text { Alimentação } \\
\text { Saudável }\end{array}$ & $X$ & $x$ & $X$ & & $x$ & $x$ & $X$ & $x$ & $x$ & & & $X$ & $X$ & $X$ & \\
\hline $\begin{array}{l}\text { Promoção da } \\
\text { Cultura de Paz e } \\
\text { Direitos } \\
\text { Humanos }\end{array}$ & $x$ & & $X$ & & $X$ & $X$ & $X$ & & $X$ & & & $X$ & $X$ & & $X$ \\
\hline $\begin{array}{l}\text { Promoção das } \\
\text { Práticas } \\
\text { Corporais, } \\
\text { Atividade Física e } \\
\text { Lazer nas Escolas }\end{array}$ & & & & & $x$ & $x$ & $X$ & & $X$ & & & & $x$ & & \\
\hline $\begin{array}{l}\text { Promoção da } \\
\text { Saúde Ambiental } \\
\text { e } \\
\text { Desenvolvimento } \\
\text { Sustentável }\end{array}$ & $x$ & & & & $x$ & & $X$ & $x$ & $X$ & & & $x$ & $x$ & & $x$ \\
\hline $\begin{array}{l}\text { Saúde e } \\
\text { Prevenção nas } \\
\text { Escolas (SPE): } \\
\text { Direito Sexual e } \\
\text { Reprodutivo e } \\
\text { Prevenção das } \\
\text { DST/AIDS }\end{array}$ & $x$ & $X$ & $X$ & & $x$ & $x$ & $X$ & $x$ & $X$ & & & $X$ & & $X$ & $X$ \\
\hline $\begin{array}{l}\text { Saúde e } \\
\text { prevenção nas } \\
\text { escolas (SPE): } \\
\text { prevenção ao } \\
\text { uso de álcool, } \\
\text { tabaco, cracke } \\
\text { outras drogas }\end{array}$ & $X$ & $X$ & $x$ & & & & & $x$ & $X$ & & & $x$ & & $x$ & $x$ \\
\hline $\begin{array}{l}\text { Saúde e } \\
\text { prevenção nas } \\
\text { escolas (SPE): } \\
\text { formação de } \\
\text { jovens } \\
\text { multiplicadores } \\
\text { para atuarem } \\
\text { entre pares nas } \\
\text { temáticas do } \\
\text { direito sexual e } \\
\text { reprodutivo e } \\
\text { prevenção de } \\
\text { DST/AIDS }\end{array}$ & & & & & & & & $x$ & $x$ & & & & $x$ & & \\
\hline
\end{tabular}

Fonte: Brasil. Simec (2016). ${ }^{16}$ 
ISSN 2179-6750

As ações integrantes do componente III, de acordo com dados, a partir dos dados disponíveis no Simec, foram as menos pactuadas e desenvolvidas nos anos de 2013, 2014 e 2015. São as ações que deveriam ser desenvolvidas para a formação dos envolvidos na execução do PSE: capacitar os profissionais em vigilância alimentar e nutricional; capacitar os profissionais para trabalhar com temáticas de promoção da alimentação saudável; capacitar os profissionais para trabalhar com direitos sexuais e direitos reprodutivos e prevenção das DST/AIDS; capacitar os profissionais para trabalhar com as temáticas: prevenção ao uso de álcool e tabaco, crack e outras drogas; capacitar os profissionais da saúde e educação em prevenção e atenção as violências; capacitar os profissionais sobre o desenvolvimento infantil; capacitar os profissionais para desenvolverem ações de promoção da Saúde nas Escolas; capacitar os profissionais para gestão intersetorial do PSE. ${ }^{16}$

Identificou-se que os M1, M4 e M5, no ano de 2013, pactuaram, mas não as realizaram. No ano de 2014, nenhum município pactuou ações e, em 2015, o M2 as pactuou, mas não desenvolveu e o M4 desenvolveu parcialmente as ações pactuadas. Nesse componente, destaca-se o M3, que pactuou e realizou expressivo número de ações nos anos de 2013 e 2015. Infere-se que os dados não tenham sido inseridos no Simec, pois os municípios receberam recursos nestes anos, que seriam enviados perante o cumprimento do mínimo necessário das pactuações.

M3 é o município com maior população, área territorial e número de escolares, sugerindo que os municípios maiores foram mais efetivos no que se refere ao componente III e que os menores tiveram dificuldade em cumprir com esta prerrogativa do programa que seria fundamental para o seu qualificado funcionamento. Sugere-se que o componente III é o que apresenta as maiores fragilidades na realidade estudada de implantação do PSE.

\section{Discussão}

A destinação de recursos à Atenção Básica em Saúde, onde se situa o PSE, alterouse após a constituição do SUS dando visibilidade às ações básicas de saúde. ${ }^{18}$ Entretanto, parece que o ambiente escolar, por não se constituir, por excelência um lugar de assistência, continuou desassistido para ser objeto de um programa de saúde/educação específico - o PSE, à época do estudo, era financiado por recursos destinados a programas (Piso da Atenção Básica variável), que não compõem o protocolo de financiamento da Atenção Básica previsto nos recursos fixos (Piso da Atenção Básica fixo). Este modelo foi alterado em 2019 pela Portaria Ministerial 2979 que instituiu o Programa Previne Brasil, 
visando estabelecer novo modelo de financiamento de custeio da Atenção Primária à Saúde no âmbito do Sistema Único de Saúde. Ela alterou o Título II da Portaria de Consolidação $n^{\circ}$ 6/GM/MS, de 28 de setembro de 2017, que estipulava a destinação de recursos a partir da definição do Piso de atenção Básica Variável e Fixo. Nesta nova Portaria a destinação dos recursos para a atenção Primária/Básica se fará pela: I - capitação ponderada; II - pagamento por desempenho; e III - incentivo para ações estratégicas. O Programa Saúde na Escola está contemplado neste último item. ${ }^{19}$

Os dados extraídos das Portarias Ministeriais mostram que no ano de 2011, quando havia o repasse integral, no momento da pactuação das ações, eles eram consideráveis, observando-se, posteriormente, nos anos de 2013 e 2015, que houve significativa diminuição. Além disso, houve o repasse de $20 \%$ no momento da pactuação e o restante após a conclusão das ações pactuadas comprovadas pela alimentação dos sistemas federais de avaliação.

Como o pagamento depende da comprovação das ações pactuadas ganha destaque a qualidade do registro dos dados que alimentam os sistemas federais que pode ser dificultado pelo baixo percentual de inserção de dados no Simec/PSE. O acompanhamento permanente feito pelo gestor permite a delimitação de seus territórios, diagnóstico situacional com base nos determinantes sociais, no cenário epidemiológico, incluindo o repasse adequado dos recursos financeiros. ${ }^{20}$

A avaliação antropométrica; atualização do calendário vacinal; detecção precoce de hipertensão arterial sistêmica; detecção precoce de agravos de saúde negligenciados prevalentes na região (hanseníase, tuberculose, malária, dentre outros); avaliação oftalmológica; avaliação auditiva; avaliação nutricional; avaliação da saúde bucal; avaliação psicossocial constam do componente I. ${ }^{21}$ Todas foram pactuadas, excetuando-se a avaliação psicossocial, conforme os termos de pactuação dos cinco municípios.

Em consonância com o estudo desenvolvido por Machado et al. (2015), ${ }^{20}$ no que se refere às ações do componente I, todas as regiões do país apresentaram resultados expressivos, variando de $69,4 \%$ a $80,5 \%$, sendo a região Norte a que mais executa atividades nesse cenário, seguidas no Nordeste, Centro-Oeste, Sul e Sudeste, respectivamente.

A obesidade e sobrepeso têm se colocado como problema comum no ambiente escolar, contrapondo-se à desnutrição. Identificá-los pode ajudar a estabelecer medidas de promoção da saúde e de prevenção que contribuam com o crescimento e desenvolvimento esperado dos escolares. ${ }^{22}$ Por outro lado, essa constatação pode sugerir que Atenção Básica em Saúde está deixando desassistida a população escolar, pois, 
deveria, mesmo fora do ambiente escolar, ter mapeado e sob cuidado a população adscrita.

Esse nível de assistência deveria estar organizado no sentido de acolher, escutar e responder de forma positiva, oferecendo resolutividade à maioria dos problemas de saúde. Ao mesmo tempo, a Atenção Básica deveria se sentir responsável pela resolução desses problemas, mesmo que demande a referência a outros pontos de atenção do sistema de saúde ${ }^{23}$ cumprindo o princípio da integralidade.

Considera-se que a escola reflete as condições epidemiológicas do seu entorno; uma escola, situada numa realidade em que os serviços de saúde atuem eficientemente, terá menor frequência em seus problemas de saúde e, quando eles existirem, serão atendidos sem que isso seja um problema a mais para os serviços, uma vez que esperados para os perfis da comunidade.

As ações do componente II, voltadas para os aspectos da educação em saúde e da promoção da saúde dos escolares ${ }^{23}$ foram igualmente contempladas nas pactuações dos municípios. Dentre elas ganhou destaque o item promoção da segurança alimentar e promoção da alimentação saudável, assim como as de saúde e prevenção nas escolas: direito sexual e reprodutivo e prevenção de DST/Aids, pactuadas em um maior número de vezes, em todos os municípios. Em contraposição, as de promoção de práticas corporais, atividade física e lazer nas escolas foram as menos pactuadas. Estudo mostrou que as práticas corporais estão entre as negligenciadas no PSE, quando se esperava que elas o compusessem; sugere a falta de ambientes e profissionais para o seu exercício. ${ }^{24}$

Pelo que se constata, a promoção da saúde, elemento deste componente, considerada expressão do conceito ampliado de saúde através de iniciativas que possibilitassem aos escolares vivenciar ambientes promotores de saúde, carece de maior destaque. Pactuaram-se em maior medida as ações preventivas e de diagnóstico precoce de possíveis agravos, em detrimento das de promoção da saúde. Nestas, a mais pactuada foi a de promoção da saúde e prevenção de agravos, sendo efetivada por meio de ações de segurança alimentar e promoção da alimentação saudável. As demais figuraram em menor frequência, assim como em estudo que levantou dados semelhantes. ${ }^{25}$

A abordagem da promoção da saúde na escola parece ser um desafio na construção do PSE, uma vez que esse referencial nem sempre é tomado em uma mesma perspectiva. A introdução da saúde no ambiente escolar foi marcada pelas ações higienistas, as quais teimam em ser hegemônicas. Construir uma cultura de promoção da saúde na escola é tarefa, portanto, a ser implementada. É certo que promover saúde, a partir do ambiente escolar, constitui-se em política pública, além de exigir o envolvimento coordenado de ações intersetoriais alicerçadas em destinação de recursos, as quais 
permitam implementar a concepção ampliada de saúde e uma educação integral coerente com o discurso que tem sido divulgado. Seu desenvolvimento exige atuação interdisciplinar, sustentada em diagnósticos das realidades localizadas, a fim de identificar os problemas reais e as soluções a partir da realidade dos sujeitos da saúde e educação tendo como princípio direitos fundamentais como o de acesso à saúde, à educação, alimentação e condições de vida. ${ }^{3,26-28}$

Estudos mostram que ainda persiste no tratamento da promoção da saúde, em especial no ambiente escolar, a visão higienista, preventivista e de definição de condutas como elementos centrais que levariam a produção da saúde em detrimento de um referencial de sustentação da promoção da saúde que extrapola o âmbito individual, ${ }^{27,28}$ e se ampara na concepção de que saúde é a expressão das políticas públicas municipais, estaduais, nacionais, e globais, as quais são determinadas pela produção e consumo característicos das formações sociais.

Pensar e encaminhar de forma coerente a promoção da saúde exige ultrapassar a perspectiva individualista que atribui aos estilos de vida das pessoas, a responsabilidade pela saúde ou pela sua falta. Promover saúde exige acesso a condições de existência que passam pelo acesso à alimentação "[...] nutritiva e saudável, a espaços adequados para o lazer, ambientes propícios para a prática de esportes, informações básicas sobre o cuidado com a saúde" [...] as quais, não "[...] dependem unicamente da mudança de hábitos individuais, mas de políticas públicas que sustentem uma concepção de sociedade, no caso brasileiro, ainda a construir". ${ }^{29,}$ p. 287

É previsto, para a execução do programa, a formação dos envolvidos (gestores, equipes de educação e de saúde), como compromisso das três esferas de governo, trabalhando de forma contínua e permanente, configurando o componente III. Suas ações deveriam prever a formação do grupo de trabalho intersetorial; formação de jovens protagonistas para o PSE/SPE; formação de profissionais da educação e saúde nos temas relevantes ao PSE; curso de prevenção do uso de drogas para educadores de escolas públicas; rede universidade aberta do Brasil. ${ }^{23}$

Esse componente foi o mais fragilizado, especialmente, nos dados acessados no Simec, em relação aos anos de 2013 a 2015. Neles se observa que, no ano de 2014, nenhuma ação foi pactuada nesse componente, em nenhum dos cinco municípios. Ao mesmo tempo, nos anos de 2013 e 2015, ações que foram pactuadas não foram realizadas, tornando problemática a avaliação desse componente. Em outro estudo, a formação para os profissionais das unidades de saúde e das escolas, assim como os gestores não foram realizadas tornando uma das dificuldades para sua implementação. ${ }^{30}$ 
As capacitações são importantes para promover a aproximação dos profissionais envolvidos no PSE, fomentar a discussão de estratégias proporcionando nivelamento técnico conceitual, de maneira que os profissionais envolvidos possam ter condições de qualificar a comunicação e o entendimento das bases conceituais do PSE. ${ }^{31}$ Os documentos do PSE não foram direcionados para indicações específicas para a formação dos envolvidos. Quando informativos eram constituídos por folders instrutivos e textos contextualizando as informações dos manuais buscando abreviar informações para gestores, profissionais de saúde e escolares. ${ }^{32}$

A formação dos envolvidos no PSE, é um compromisso das três esferas de governo e deve ser trabalhado de maneira contínua e permanente, com base no estabelecimento de articulações interinstitucionais e instersetoriais que desenvolvam necessidades de formação para a transformação das práticas em saúde; a construção de políticas públicas integradas é condição indispensável para atualização e renovação, de forma permanente, da educação e da saúde, com vistas à integralidade. ${ }^{10}$

\section{Conclusão}

Os municípios pactuaram números mais expressivos, de ações de avaliação das condições de saúde, item do Componente I do PSE, verificadas nos termos de pactuação do ano de 2015. Contudo, desde a implantação do programa, o Ministério da Saúde, responsável pela sistematização dos dados desse componente, com base no e-SUS, não apresentou nenhum relatório desse cenário, dificultando o acompanhamento e monitoramento desse item. Destacaram-se neste componente as avaliações clínicas dos alunos com maior enfoque aos aspectos assistenciais da saúde deste grupo.

Quanto ao Componente II, que contempla as questões de promoção da saúde à prevenção dos agravos identificou-se que as pactuações mais frequentes foram para o item promoção da segurança alimentar e promoção da alimentação saudável e saúde, bem como da prevenção nas escolas: direito sexual e reprodutivo e prevenção de DST/AIDS; porém, identifica-se uma fragilidade na pactuação do item promoção das práticas corporais, atividade física e lazer nas escolas. A promoção da saúde precisaria compor as políticas públicas, de forma que as ações na escola pudessem alcançar para além das prescrições individuais de normas para se ter saúde.

Os municípios pesquisados são, como descritos pequenos e, pelo que se verifica, os menores, tiveram poucas atividades de formação indicando que esta dimensão do programa precisa ser reconstruída, uma vez que na condição de municípios pequenos, nem sempre havia disponibilidade de recursos humanos para atuar nas questões atinentes 
ao programa, quanto mais para levar a efeito a formação dos envolvidos. Daí a indicação de que esta ação pudesse ser articulada pela gestão regional.

Ao buscar responder a questão inicial de como tem ocorrido a implantação do PSE pelo desenvolvimento dos seus componentes, é possível indicar que o programa, talvez por ser recente, possui fragilidades, principalmente nas ações que requerem atuação intersetorial; constatação evidenciada pelas escassas ações voltadas para o componente III, o qual centra-se na formação continuada de todos os profissionais envolvidos no programa.

O programa foi implantado nos municípios, mas é um desafio que requer organização institucional para o desenvolvimento de todos os componentes previstos.

\section{Referências}

1. Pettres $A M$, Da Ros, MA. A determinação social da saúde e a promoção da saúde. Arq Catarinense Med. 2018 [citado 6 maio 2020];47(3):183-96. Disponível em: http://www.acm.org.br/acm/seer/index.php/arquivos/article/view/375/282.

2. Figueiredo TAM, Machado VLT, Abreu MMS. A saúde na escola: um breve resgate histórico. Cien Saude Colet. 2010;15(2):397-402. https://doi.org/10.1590/S141381232010000200015.

3. Casemiro JP, Fonseca A BC, Secco FVM. Promover saúde na escola: reflexões a partir de uma revisão sobre saúde escolar na América Latina. Cien Saude Colet. 2014;19(3):829-40. https://doi.org/10.1590/1413-81232014193.00442013.

4. Ministério da Saúde (BR). Portaria Interministerial n. 749, de 13 de maio de 2005. Constitui a Câmara Intersetorial para a elaboração de diretrizes com a finalidade de subsidiar a Política Nacional de Educação em Saúde na Escola. Brasília (DF): [Diário Oficial da União]; 2005 [citado 4 abr. 2015]. Disponível em: http://www.funasa.gov.br/site/wpcontent/files_mf/Pi_749_2005.pdf.

5. Ministério da Saúde (BR). Portaria Interministerial n. 1.820, de 01 de agosto de 2006. Altera os arts $1^{\circ}, 2^{\circ}$ e $3^{\circ}$ da Portaria Interministerial $n^{\circ} 749$, de 13 de maio de 2005. Brasília (DF): [Diário Oficial da União]; 2006 [citado 2 abr. 2015]. Disponível em: http://bvsms.saude.gov.br/bvs/saudelegis/gm/2006/pri1820_01_08_2006.html.

6. Brasil. Decreto Presidencial n. 6.286, de 5 de dezembro de 2007. Institui o Programa Saúde na Escola - PSE, e dá outras providências. Brasília (DF): [Diário Oficial da União]; 2007 [citado 9 jun 2014]. Disponível em: http://www.planalto.gov.br/ccivil_03/_ato20072010/2007/decreto/d6286.htm. 
7. Ministério da Saúde (BR). Portaria Interministerial n. 1.413, de 10 de julho de 2013. Redefine as regras para adesão ao Programa Saúde na Escola (PSE) por Estados, Distrito Federal e Municípios e dispõe sobre o respectivo incentivo financeiro para custeio de ações. Brasília (DF): [Diário Oficial da União]; 2013 [citado 2 nov. 2014]. Disponível em: http://bvsms.saude.gov.br/bvs/saudelegis/gm/2013/pri1413_10_07_2013.html.

8. Fracolli LA, Zoboli ELP, Granja GF, Ermel RC. Conceito e prática da integralidade na atenção básica: a percepção das enfermeiras. Rev Esc Enferm USP. 2011;45(5):1135-41. https://doi.org/10.1590/S0080-62342011000500015.

9. Sousa MC. Saúde na escola: analisando os caminhos da intersetorialidade [dissertação]. [Salvador]: Universidade Federal da Bahia; 2014.

10. Ministério da Saúde (BR). Caderno do gestor do PSE. Brasília (DF): [MS]; 2015 [citado 25 jun 2016]. Disponível em:

http://bvsms.saude.gov.br/bvs/publicacoes/caderno_gestor_pse.pdf.

11. IBGE. Informações estatísticas das cidades. 2016 [citado 21 ago. 2016]. Disponível em: http://cidades.ibge.gov.br/xtras/home.php.

12. Minayo MCS. O desafio do conhecimento: pesquisa qualitativa em saúde. 13a ed. São Paulo: Hucitec; 2013.

13. Ministério da Saúde (BR). Portaria n. 3.014, de 20 de dezembro de 2011. Habilita Municípios e o Distrito Federal para o recebimento do repasse de recursos financeiros relativos ao Programa Saúde na Escola (PSE). Brasília (DF): [Diário Oficial da União]; 2011 [citado 25 out. 2015]. Disponível em:

http://bvsms.saude.gov.br/bvs/saudelegis/gm/2011/prt3014_19_12_2011.html.

14. Ministério da Saúde (BR). Portaria n. 524, de 26 de março de 2012. Habilita Municípios ao recebimento do repasse de recursos financeiros relativos ao Programa Saúde na Escola (PSE). Brasília (DF): [Diário Oficial da União]; 2012 [citado 25 out. 2015]. Disponível em: http://bvsms.saude.gov.br/bvs/saudelegis/gm/2012/prt0524_26_03_2012.html.

15. Ministério da Saúde (BR). Portaria n. 2.608, de 31 de outubro de 2013. Define Municípios com adesão ao Programa Saúde na Escola de 2013 e os habilita ao recebimento de $20 \%$ (vinte por cento) do teto de recursos financeiros pactuados em Termo de Compromisso e dá outras providências. Brasília (DF): [Diário Oficial da União]; 2013 [citado 25 out. 2015]. Disponível em: http://bvsms.saude.gov.br/bvs/saudelegis/gm/2013/prt2608_31_10_2013.html. 
16. Ministério da Saúde (BR). Portaria n. 1.067, de 23 de julho de 2015. Define Municípios com adesão ao Programa Saúde na Escola em 2014 e os habilita ao recebimento de $20 \%$ (vinte por cento) do teto de recursos financeiros pactuados em Termo de Compromisso e dá outras providências. Brasília (DF): [Diário Oficial da União]; 2015 [citado 20 out. 2015]. Disponível em: http://bvsms.saude.gov.br/bvs/saudelegis/gm/2015/prt1067_23_07_2015.html.

17. Ministério da Educação (BR). Sistema Integrado de Monitoramento Execução e Controle (Simec). Brasília (DF): [Diário Oficial da União]; 2016. [citado 10 maio 2016]. Disponível em: http://simec.mec.gov.br/.

18. Barbosa MG, Zortea AG, Cunha FM, Santos TC, Ribeiro DT, Nascimento DT, et al. Financiamento da Atenção Básica à Saúde No Brasil: do piso da atenção básica à remuneração por desempenho. In: Rede Unida: Atenção básica: olhares a partir do programa nacional de melhoria do acesso e da qualidade - (PMAQ-AB). Porto Alegre: Rede Unida; 2016. p. 101-123.

19. Ministério da Saúde (BR). Gabinete do Ministro. Portaria n. 2.979, de 12 de novembro de 2019. Institui o Programa Previne Brasil, que estabelece novo modelo de financiamento de custeio da Atenção Primária à Saúde no âmbito do Sistema Único de Saúde, por meio da alteração da Portaria de Consolidação n. 6/GM/MS, de 28 de setembro de 2017. Brasília (DF): Diário Oficial da União; 13 nov. 2019 [citado 6 maio 2020]. Disponível em: http://www.in.gov.br/en/web/dou/-/portaria-n-2.979-de-12-de-novembro-de-2019227652180

20. Machado MFAS, Gubert FA, Meyer APGFV, Sampaio YPCC, Dias MAS, Almeida ANB, et al. Programa saúde na escola: estratégia promotora de saúde na atenção básica no Brasil. J Hum Growth Dev. 2015;25(3):307-12. http://dx.doi.org/10.7322/jhgd.96709

21. Ministério da Saúde (BR), Ministério da Educação (BR). Passo a passo programa saúde na escola (PSE): tecendo caminhos da intersetorialidade. Brasília (DF): Ministério da Saúde; 2011 [citado 25 maio 2014]. Disponível em:

http://bvsms.saude.gov.br/bvs/publicacoes/passo_a_passo_programa_saude_escola.pdf.

22. Souza MHN, Silveira GS, Pinto AFS, Sodré VRD, Ghelman LD. Avaliação do estado nutricional e da saúde de crianças e adolescentes na prática assistencial do enfermeiro. Cogitare Enferm. 2013;18(1):29-35. http://dx.doi.org/10.5380/ce.v18i1.28926.

23. Ministério da Saúde (BR). Portaria n. 2.488, de 21 de outubro de 2011. Dispõe sobre a aprovação da Política Nacional de Atenção Básica. Brasília (DF): [Diário Oficial da União]; 
2011. [citado 24 jun. 2016]. Disponível em:

ISSN 2179-6750

http://bvsms.saude.gov.br/bvs/saudelegis/gm/2011/prt2488_21_10_2011.html.

24. Silvestre $\mathrm{C}$, Almeida J, Conceição $\mathrm{MH}$, Albuquerque OM. Análise de promoção das práticas corporais e atividade física propostas pelo Programa Saúde na Escola nas escolas de Samambaia/Distrito Federal. Atas - Invest Qual. 2016;2:1645-52.

25. Machado WD, Oliveira KMCP, Cunha CG, Araújo Junior DG, Silvino RHS, Dias MAS. "Programa saúde na escola": um olhar sobre a avaliação dos componentes. SANARE, Sobral. 2016;15(1):62-8.

26. Graciano AMC, Cardoso NMM, Mattos FF, Gomes VE, Oliveira ACB. Promoção da saúde na escola: história e perspectivas. J Health Biol Sci. 2015;3(1):34-8. http://dx.doi.org/10.12662/2317-3076jhbs.v3i1.110.p34-38.2015

27. Costa GMC, Cavalcanti VM, Barbosa ML, Celino SDM, França ISX, Sousa FS. Promoção de saúde nas escolas na perspectiva de professores do ensino fundamental. Rev Eletr Enferm. 2013;15(2):506-15. https://doi.org/10.5216/ree.v15i2.15769.

28. Couto NA, Kleinpaul WV, Borfe L, Vargas SC, Pohl HH, Krug SBF. O ambiente escolar e as ações de promoção da saúde. Cinergis, Santa Cruz do Sul. 2016;17(Supl.1):378-83. http://dx.doi.org/10.17058/cinergis.v17i0.8150.

29. Furtado MA, Szapiro AM. Política Nacional de Promoção da Saúde: os dilemas da autonomização. Saude Soc. 2016;25(2):277-89.

30. Faial LCM, Silva RCMRS, Pereira ER, Refrande SM, Souza LMC, Faial CSG. A escola como campo de promoção à saúde na adolescência: revisão literária. Rev Pró-UniverSUS. 2016;7(2):22-9.

31. Ferreira IRC, Moysés SJ, França BHS, Carvalho ML, Moysés ST. Percepções de gestores locais sobre a intersetorialidade no Programa saúde na escola. Rev Bras Educ. 2014;19(56):61-78. https://doi.org/10.1590/S1413-24782014000100004.

32. Dias MAS, Gomes DF, Branco RB, Brito MCC, Silva LCC, Silva AV. Programa Saúde na Escola: tecendo uma análise nos documentos oficiais. SANARE, Sobral. 2014;13(1):29-34. 
Rosa Maria Rodrigues | ORCiD: 0000-0002-7047-037X.

Enfermeira. Doutora em Educação. Professora Associada, Mestrado e Doutorado em Biociências e Saúde e na Graduação em Enfermagem da Universidade Estadual do Oeste do Paraná Cascavel, PR, Brasil.

Gilson Fernandes da Silva | ORCiD: 0000-0001-9107-2656.

Mestre em Biociências e Saúde pela Universidade Estadual do Oeste do Paraná (UNIOESTE/Cascavel), PR. Graduado em Enfermagem pela Universidade Paranaense (UNIPAR/Cascavel), PR. Enfermeiro/Gerente da Escola de Saúde Pública Municipal, Coordenador e Tutor do Programa de Residência Multiprofissional em Saúde da Família de Cascavel da Secretaria Municipal de Saúde. Cascavel, PR. Brasil. Brasil.

Solange de Fátima Reis Conterno | ORCiD: 0000-0003-2493-8071.

Graduada em Pedagogia, Doutora em Educação. Professora no Curso de Graduação em Enfermagem e Docente Colaboradora no Programa de Pós Graduação Stricto Sensu em Biociências e Saúde da Universidade Estadual do Oeste do Paraná Cascavel, PR, Brasil.

Claudia Silveira Vieira | ORCiD: 0000-0002-0900-4660.

Enfermeira. Doutora em Enfermagem em Saúde Pública, Pós Doutora em seguimento do RecémNascido de risco. Professora Associada no mestrado e Doutorado em Biociências e Saúde e na Graduação em Enfermagem da Universidade Estadual do Oeste do Paraná, Cascavel, PR, Brasil.

Lourdes Missio | ORCiD: 0000-0002-3419-5817.

Enfermeira, Doutora em Educação. Professora no Curso de Pós-Graduação em Ensino em Saúde e na Graduação em Enfermagem da Universidade Estadual do Mato Grosso do Sul, Dourados, MS, Brasil. 